\title{
Meet interesting abbreviations in clinical mass spectrometry: from compound classification by REIMS to multimodal and mass spectrometry imaging (MSI)
}

\author{
D. LUPTÁKOVÁ ${ }^{1,2,3}$, T. PLUHÁČEK ${ }^{1,4}$, A. PALYZOVÁ ${ }^{1}$, J. PŘICHYSTAL ${ }^{1,4}$, J. BALOG ${ }^{5}$, K. LEMR $^{1,4}$, I. JURÁNEK $^{2}$, \\ V. HAVLÍČEK ${ }^{1,4^{*}}$
}

\begin{abstract}
${ }^{1}$ Institute of Microbiology of the CAS, v.v.i., Videnska 1083, 142 20, Prague 4, Czech Republic; ${ }^{2}$ Laboratory of Molecular Pharmacology, Institute of Experimental Pharmacology and Toxicology, Slovak Academy of Sciences, Bratislava, Slovak Republic; ${ }^{3}$ Department of Pharmacology, Jessenius Faculty of Medicine, Comenius University Bratislava, BioMed Martin, Slovak Republic; ${ }^{4}$ Regional Centre of Advanced Technologies and Materials, Department of Analytical Chemistry, Faculty of Science of Palacky

University in Olomouc, Olomouc, Czech Republic; ${ }^{5}$ Waters Research Center, Zahony street 1031, Budapest, Hungary
\end{abstract}

\begin{abstract}
Summary. - This feature article discusses two modern mass spectrometry abbreviations in their clinical applications. Rapid evaporative ionization mass spectrometry (REIMS) is reported as a molecular classification tool useful for spectral features definition prior to mass spectrometry imaging (MSI). REIMS is appreciated not only as an ionization technique coupled with a surgical device but particularly as a biomarker discovery tool. For more complex understanding of pathological processes at cellular and molecular levels, the importance of multimodal approach in imaging applications is documented in the context of fiducial markers needed for hyperspectral data fusion collected by optical microscopy, elemental and molecular MSI. Finally, pathogen inactivation needed prior to the sectioning of the infected tissue is reported, and the impact of formaldehyde crosslinking to signal reduction is discussed.
\end{abstract}

Keywords: REIMS; multimodal; mass spectrometry imaging; fiducial markers; pathogen inactivation

\section{Introduction}

In the past decade, clinical mass spectrometry has undergone a tremendous instrumental and application development. Clinical microbiology has become one of the most growing analytical fields, particularly due to the standardization of the microbial ribosomal protein typing that has spread into many microbiology laboratories and has

${ }^{*}$ Corresponding author. E-mail: vlhavlic@biomed.cas.cz; phone: +420-2-41062786.

Abbreviations: DESI $=$ desorption electrospray ionization; FC = ferricrocin; $\mathrm{HI}=$ hypoxic-ischemic; $\mathrm{HII}$ = hypoxia-ischemiainsulted; iKnife = intelligent knife; LA-ICP = laser ablation with inductively coupled plasma; $\mathrm{LB}=$ Luria-Bertani; $\mathrm{LD}=$ linear discriminant; LDA = linear discriminant analysis; MALDI = matrix assisted laser desorption ionization; MEB = malt extract broth; MS = mass spectrometry; $\mathrm{MSI}=\mathrm{MS}$ imaging; $\mathrm{PCA}=$ principal component analysis; PsF = Pseudomonas agar F; REIMS = rapid evaporative ionization mass spectrometry; SIMS = secondary ion mass spectrometry; $\mathrm{SP}=$ sporulation medium; TAFC = triacetyl fusarinine $\mathrm{C} ; \mathrm{YM}=$ yeast medium become a new diagnostic standard for characterization of bacteria, yeasts and fungi (Havlicek et al., 2013). The protein mass fingerprinting was successfully commercialized and is now represented by thousands of installations of benchtop matrix assisted laser desorption ionization-time of flight mass spectrometry (MALDI-TOF) instruments worldwide. Interestingly, the characterization of viruses has not been as commercially successful if based either on protein (Mancone et al., 2013) or gene level (Leveque et al., 2014). This may be why clinical analytical chemists are now switching their gears to metabolomics and mass spectrometry in the field of disease biomarker discovery (Prichystal et al., 2016). The reasons are twofold. Small molecules are ideal species to be efficiently and/or selectively ionized and analyzed by sensitive mass spectrometers. Second, combinations of separations and enrichment/depletion techniques with mass spectrometry may provide a very high dynamic analytical range required for distinguishing disease states from physiological conditions even when working with analytes in very complex biological matrices. Biological specimens like tissues and body fluids certainly belong to such a category. 
This feature article is dedicated to two relatively new mass spectrometry tools that have revolutionized the field of clinical mass spectrometry in the past decade: rapid evaporative ionization mass spectrometry (REIMS) and mass spectrometry imaging (MSI). Both tools can be used in concert: whereas REIMS can be applied for initial compound classification, the distinct features pre-defined by REIMS can be visualized by MSI.

\section{REIMS in surgery}

The first reports on REIMS published by Zoltan Takats' research teams in Germany and Hungary were dedicated to findings using standard surgical equipment; mass spectra were found to be highly specific to the histological type of the tissues (Balog et al., 2010). Ions were produced by REIMS mechanism; the tissue analysis was based on different phospholipid distributions within the tissue specimen; the identification algorithms used a combination of principal component analysis (PCA) and linear discriminant analysis (LDA). Although electrosurgery itself was demonstrated to directly produce gaseous ions, post-ionization methods were needed to enhance the ion yield, especially in cases when the ion current produced by the applied electrosurgical method was not sufficient for sensitive mass spectrometry (MS) analysis (Guenther et al., 2011). Tumor tissue definition was one of the most exciting clinical niches in which REIMS was successfully applied (Balog et al., 2013).

In standard REIMS surgery experiment, the tissue is dissected by a flat monopolar handpiece cutting device (St John et al., 2016). During the in vivo mass spectrometry ex- periment; the cutting device itself is kept on a small electric potential of selected polarity, whereas the opposite potential is applied onto the operated object mounted on a conductive surface (Fig. 1). The smoke generated during the cutting process contains a considerable amount of neutral or ionic aerosol, which can be transferred with the facilitation of a Venturi pump into the atmospheric pressure chamber of mass spectrometer. This online combination provides a near-real-time characterization of the tissue with a delay representing just few seconds. In one of the earliest clinical studies, REIMS accurately differentiated between distinct histological and histopathological human tissue types right in a surgical theatre (Balog et al., 2013). Soon, REIMS has been developed to an endoscopic polypectomy snare allowing in vivo analysis of the gastrointestinal tract (Balog et al., 2015). It was shown to effectively differentiate between healthy layers of the intestinal wall, cancer tissue, and adenomatous polyps based on the REIMS fingerprint of each tissue type in vivo. In another application, REIMS was used for the analysis of the colonic mucosal lipidome in colorectal cancer (Kinross et al., 2016; Muirhead et al., 2015).

The REIMS ion source was soon commercialized by Waters Corporation (United Kingdom) as a part of intelligent knife (iKnife). The product involves a heated impactor facilitating the thermal ionization of neutrals present in the dust originated from the electrosurgery. At present, the device is sold as "research only" as it is does not have regulatory approval for use in the clinical diagnostic environment. On the other hand, a number of experimental medical applications on patients is increasing and include e.g. ovarian or colorectal cancer interventions (Alexander et al., 2017; Phelps et al., 2016).

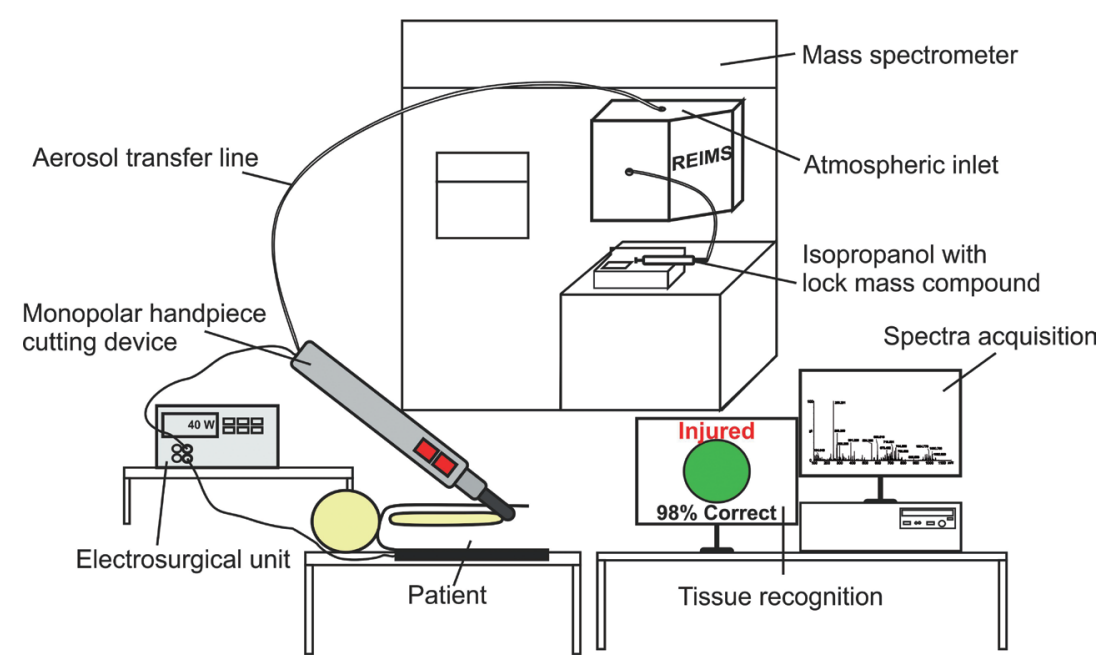

Fig. 1

Schematic presentation of the REIMS experiment 


\section{Classification of small molecules by REIMS}

Near-to-real time mass spectrometry analysis with almost no sample preparation is possible with iKnife consisting of an electro-surgical scalpel sampling analytes and REIMS. Powerful ability of REIMS tissue characterization and differentiation is used for several non-clinical applications such as food quality control studies and in research studies in microbiology and animal research. Possible adulteration of meat products can also be easily detected by REIMS (Verplanken et al., 2017). The characterization of meat originating from different species (horse, cattle, and venison) was demonstrated with high accuracy using mixed patties with a $5 \%$ detection limit (Balog et al., 2016). REIMS was also soon identified as a prospective tool for bacterial metabolomics (Strittmatter et al., 2013). The original work was extended to yeasts and fungi (Bolt et al., 2016; Cameron et al., 2016), although it is still being focused rather to a statistic approach and not to the actual structure identification of microbial metabolites (Strittmatter et al., 2014).

An amazing classification power of REIMS technology is documented on the example from experimental study on animals simulating hypoxic-ischemic encephalopathy in humans (Placha et al., 2016). Differentiation of neonatal rat brain tissues based on developmental stage and maturation of the brain and the characterization of hypoxic-ischemic (HI) injury in time has been shown. Although the brain damage development was not apparent from the REIMS negative ion mass spectra as expected for severe neurodegenerated brain tissue (Fig. 2), the statistical evaluation of the REIMS data provided distinct clustering (Fig. 3). The correct identification of mass spectral features in REIMS data and mutual distinguishing of "healthy" and "pathological" molecular biomarkers may enable the researchers to define

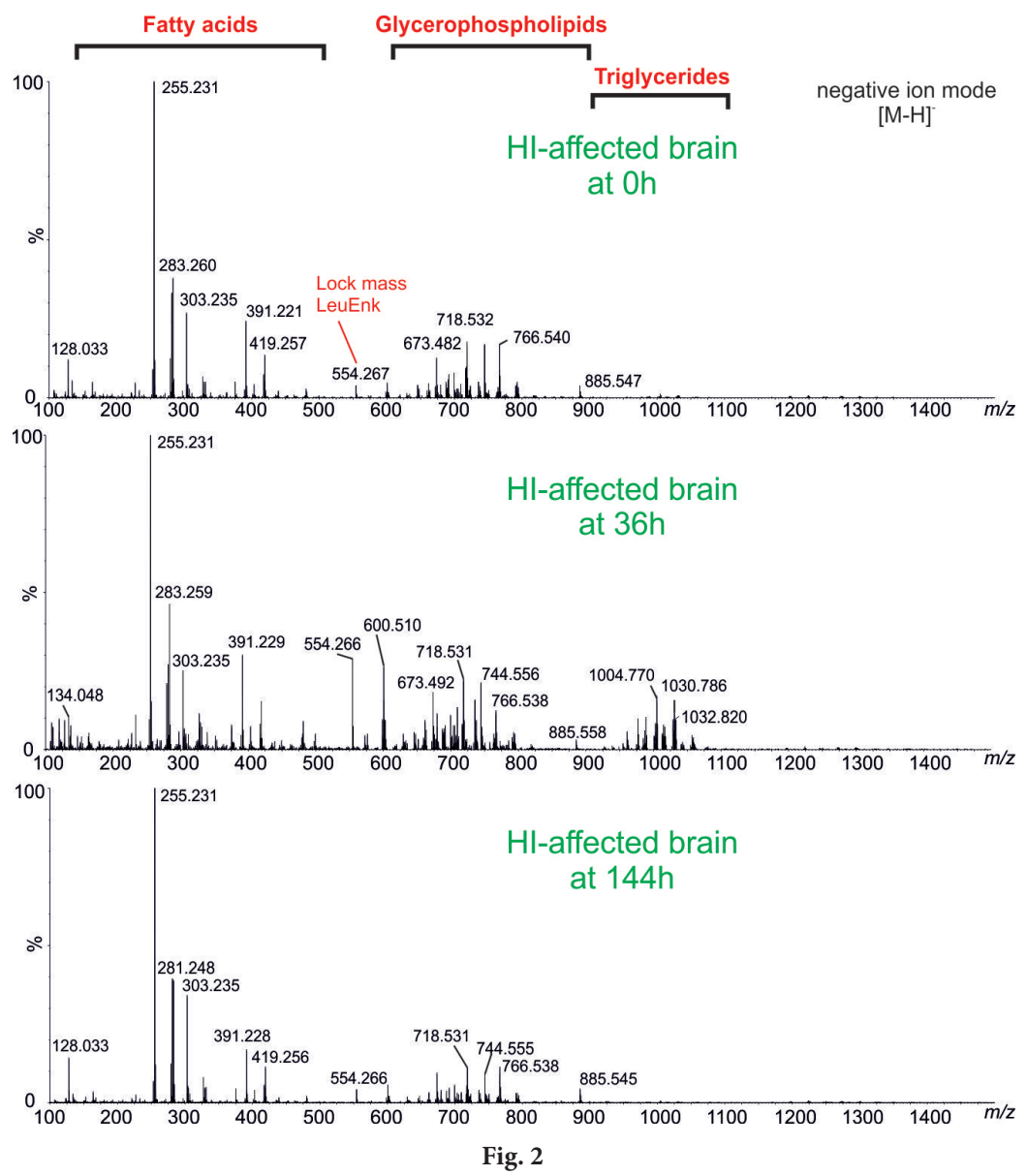

The REIMS-acquired characteristic mass spectra from the hypoxia-ischemia-affected neonatal rat brain at time intervals $0 \mathrm{~h}$ (top), $36 \mathrm{~h}$ (middle), and $144 \mathrm{~h}$ (bottom) after the insult

The negative ion spectra revealed the presence of small fatty acids in the mass range from 100 to $500 \mathrm{Da}$, larger glycerophospholipids in the mass range from 600 to $900 \mathrm{Da}$ and triglycerides in the 900-1100 Da range as molecular markers of the hypoxic-ischemic insult. Some diglycerides and sulfatides have also been identified. 
the future possible treatment interventions that may prevent the permanent brain damage which would otherwise occur upon the HI insult.

\section{From MSI to multimodal imaging}

MSI represents a second logical step after small molecule classification by REIMS. The ions identified by REIMS can consequently be probed in biological tissue material. However, single MSI is often not sufficient and more imaging tools have to be used in concert to solve specific biological questions (Pluhacek et al., 2016).

MSI was introduced in early sixties by a French couple, who used secondary ion mass spectrometry (SIMS) MSI for visualization of inorganic ions (Castaing and Slodzian, 1962). Molecular species were first probed by Bernhard Spengler who showed the distribution of peptides at one of the previous American Society for Mass Spectrometry Conferences (1994). But it was Richard Caprioli who fully rediscovered molecular MSI for biological applications, published the first peer reviewed work (Stoeckli et al., 1999) and received a US patent. Although the patent could easily be terminated due to the lack of novelty, Caprioli defined a new promising research trend, which nowadays is illustrated by three MSI papers being published daily. At present, all important mass spectrometry vendors offer the complete MSI package involving now either MALDI, SIMS, laser ablation with inductively-coupled plasma (LA-ICP), laser ablation combined with electrospray ionization, liquid bridge combined with micro- or nano-electrospray, or desorption electrospray ionization (DESI) mass spectrometry imaging. In addition to commercial tools, there is also a long list of experimental approaches in the literature.

Unequivocal localization of the components and biomolecules in complex environment including tissue sections is barely possible by using a single imaging technique. The multimodal fusion and its interrogation with histology evaluation represents a current standard approach in medically important areas. And it brings a complex overview of the analyzed (patho)physiological features within the tissue together with the precise information of local molecular composition of the tissue surface (Chughtai et al., 2012). For the combination of hyperspectral data obtained from molecular or elemental imaging mass spectrometry and optical microscopy, all performed on consecutive sections from one tissue sample, the application of fiducial markers (points of reference) is needed to implement a correct image co-registration (Fig. 4). Another important application of fiducial markers is the co-registration of more layers into a single three-dimensional object (3D imaging).

An important attribute of fiducial markers mixture should be its compatibility with all imaging techniques used to ensure correct overlay of the obtained images. As an example, fiducial marker mixture composed of Rhodamine B $(10 \mathrm{mg} / \mathrm{ml})$, ionic silver $(100 \mu \mathrm{g} / \mathrm{ml})$ and $100 \mathrm{~nm}$ gold nanoparticles $(5 \mu \mathrm{g} / \mathrm{ml})$ in poly[ $\mathrm{N}$-(2-hydroxypropyl) methacrylamide] solution (100 mg/ $\mathrm{ml}$ ) was spiked into rat bulk kidney tissue with an insulin-type syringe (300 $\mu \mathrm{m}$ needle outer diameter (OD)). The frozen tissue sections obtained with a cryomicrotome were then placed on an indium tin oxide glass (MALDI, LA-ICP) or a Prosolia Omni Slide ${ }^{\mathrm{TM}}$ glass (DESI) and dried. Mass spectrometry data were collected on SolariX 12 FTICR (Bruker Daltonics, USA), quadrupole ICP-MS 7700x spectrometer (Agilent Technologies, Japan) and Synapt G2-Si Q-TOF (Waters Corporation, United Kingdom), respectively. The multisensor data fusion is illustrated in Fig. 4. The fiducial mixture generated signals in all three probed MSI techniques and the successful detection of fiducial spots allowed us to acquire correct overlay of images in multimodal approach enabling the direct comparison of the same signals from MALDI and DESI MSI. Nanoparticles of Au and ionic Ag were both visible by LA-ICP-MSI.

\section{Infectious tissue sample handling}

To avoid variation in biomolecule content within the tissue, the quick ex vivo fixation and permanent stabilization of the sample is inevitable. In addition, it is of particular challenge to analyze infectious tissues (Cazares et al., 2015). When collecting the mass spectrometry imaging data on infected tissues, the corresponding safe sample handling protocols need to be applied. The pathogen inactivation can be provided using various physical and chemical treatments. Cryo-preservation (Day and Stacey, 2007), heating and micro-waving (Mayers, 1970) are used among the usually applied physical methods. The most common chemical treatment is formalin fixation; in case of MSI also the formalin-fixed paraffin-embedding. A new fixative non-crosslinking medium PAXgene Tissue (PAXgene) was recently developed (Loibner et al., 2016).

For standardization of microbial strain inactivation by formaldehyde solutions, we probed two microbial strains of biosafety level 2 risk category. Aspergillus fumigatus CCF 1059 and Pseudomonas aeruginosa ATCC 15692 were grown on the selective yeast medium (YM; $0.3 \%$ malt extract, $0.3 \%$ yeast extract, $0.5 \%$ peptone, $0.5 \%$ glucose) and Luria-Bertani broth (LB; $1 \%$ tryptone, $0.5 \%$ yeast extract, $1 \% \mathrm{NaCl}$ ), respectively. After the cultivation of both strains on agar plates, the agar pieces $(1 \mathrm{x} 1$ $\mathrm{cm})$ were sterile cut and incubated in formaldehyde solutions of variable concentrations (1, 2, 4, and 10\%) for 10, 30, 60, 120 $\mathrm{min}$, and $24 \mathrm{~h}$. After incubation in formaldehyde solutions, agar pieces were placed into the solid and liquid media: YM, Pseudomonas agar F (PsF; Merck), malt extract broth (MEB; BD Difco) or LB to determine the total number of viable cells. In our hands, the bacterial strain $P$. aeruginosa lost their viability upon one-hour treatment in $1 \%$ formaldehyde (Fig. 5). 


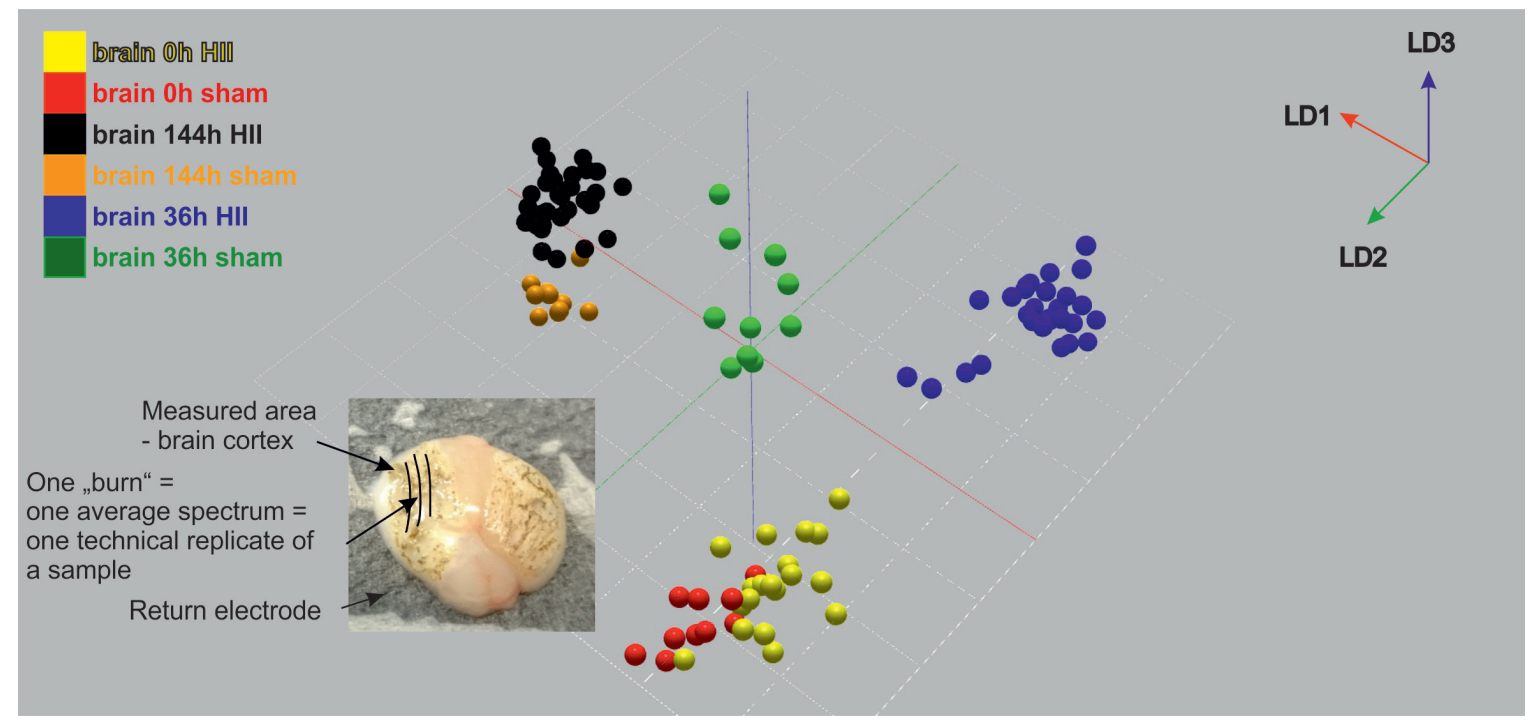

Fig. 3

Pseudo-three-dimensional plot of the data reflecting the classification of hypoxia-ischemia-insulted (HII) and control (sham) neonatal rat brains at three time intervals $(0,36$, and $144 \mathrm{~h}$ after the insult)

Axes represent projection coordinates of linear discriminant LD1 (red), LD2 (green) and LD3 (blue). Each point represents one averaged mass spectrum indicating one "burn" from the appropriate brain group. Inset shows the neonatal rat brain sample after the REIMS analysis. For the burns see the inset.
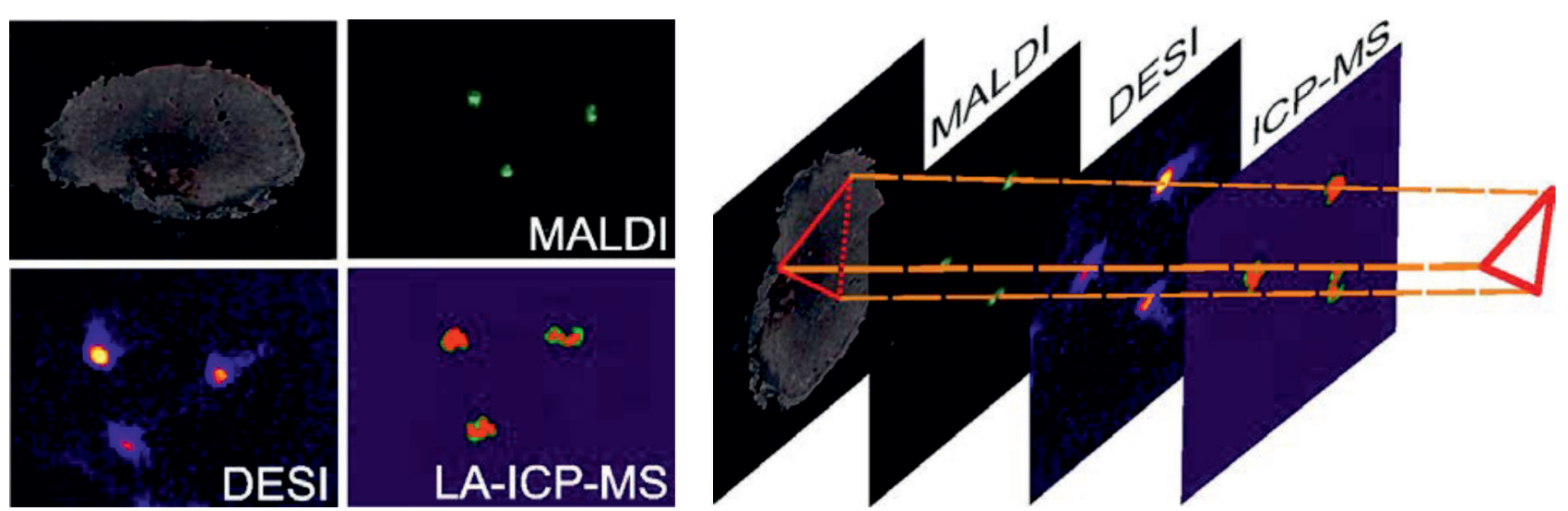

Fig. 4

Fiducial markers visualized by four imaging techniques in rat kidney tissue sections (optical scan, MALDI, DESI: Rhodamine B - m/z 443.3; LAICP-MS: ${ }^{197} \mathrm{Au}$, all on the left), right: an overlay of fiducial marker layers

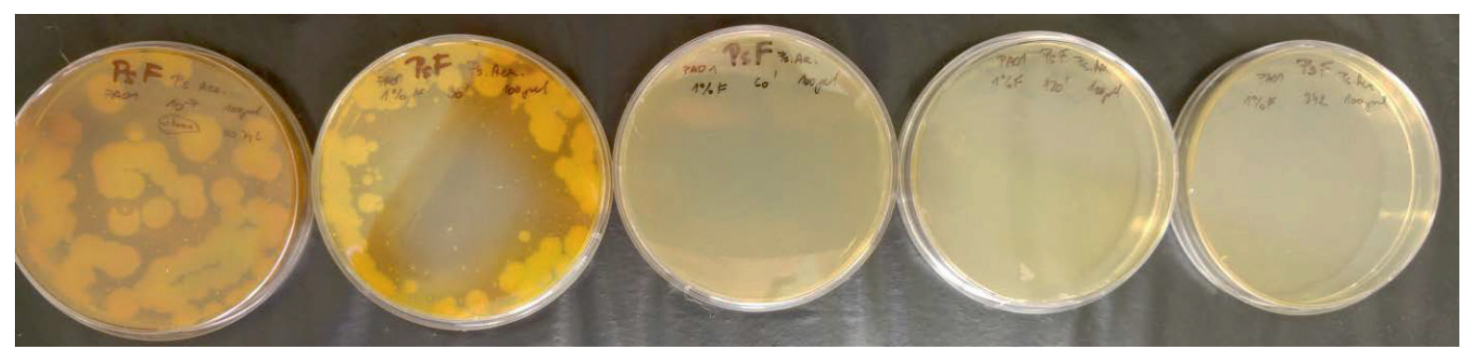

Fig. 5

Growth of $P$. aeruginosa colonies on PsF agar plates after 0, 30, 60, $120 \mathrm{~min}$, and $24 \mathrm{~h}$ incubation of bacterial suspension in $1 \%$ formaldehyde 


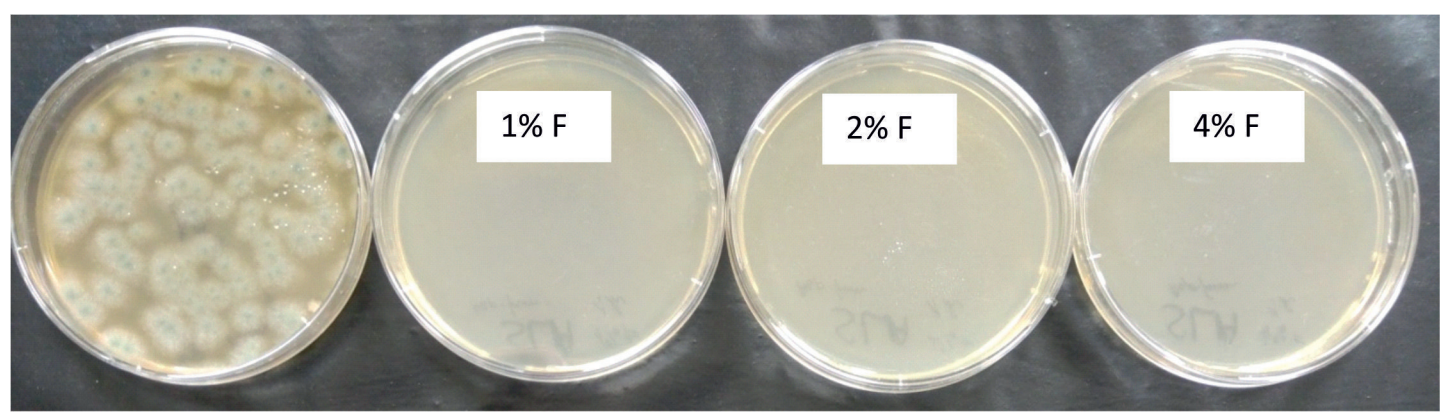

Fig. 6

A. fumigatus (collection strain) colonies grown on YM plates after 0 min and 60 min incubation in 1, 2, and 4\% formaldehyde solutions Note that virulence can significantly be modulated upon a passage.

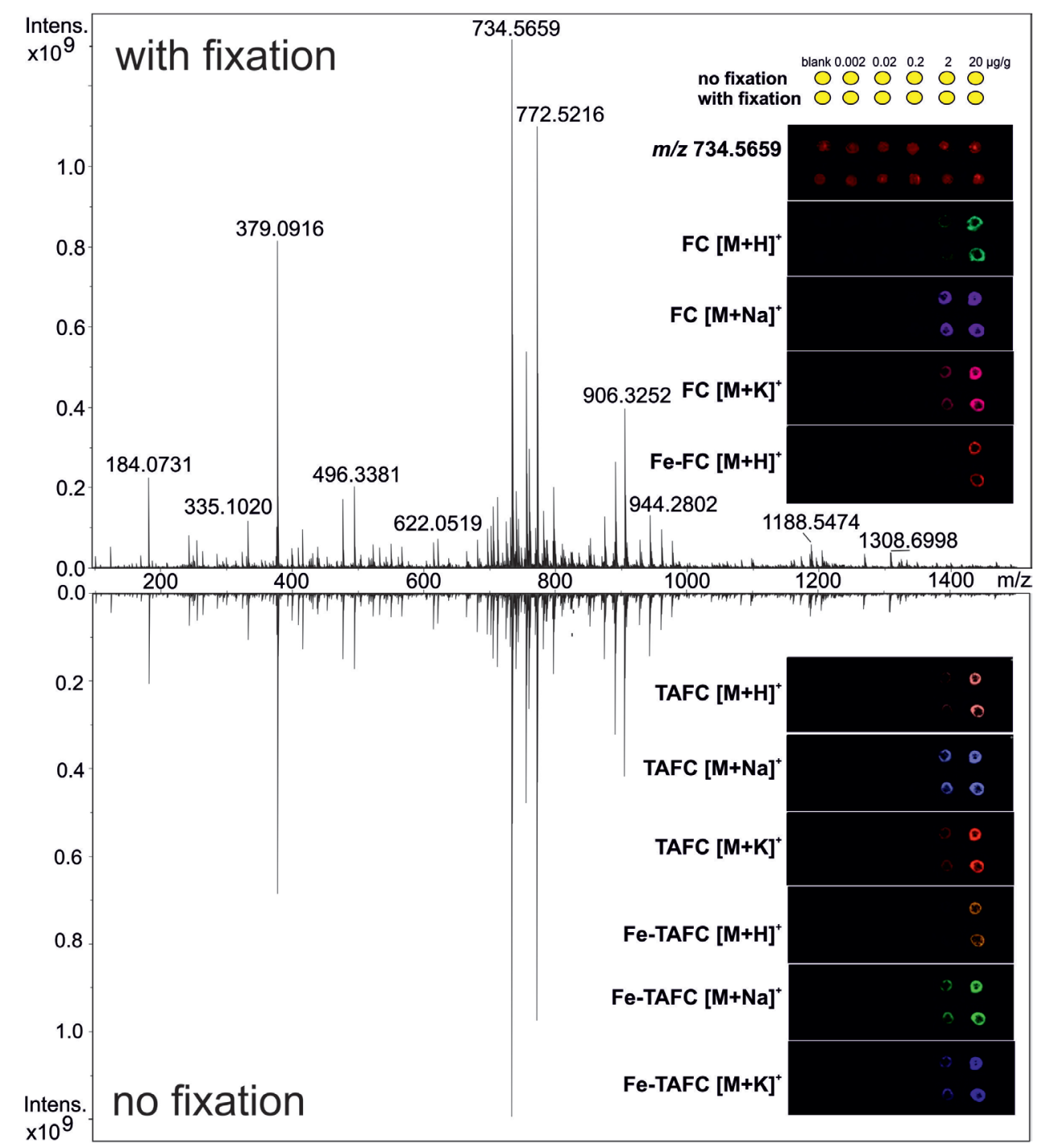

Fig. 7

MALDI mass spectra of fungal TAFC and FC in tissue homogenate after (top) and before the formaldehyde fixation (bottom) Note the production of $[\mathrm{TAFC}+\mathrm{Fe}-2 \mathrm{H}]^{+}$and $[\mathrm{FC}+\mathrm{Fe}-2 \mathrm{H}]^{+}$at $\mathrm{m} / \mathrm{z} 906$ and 771 , respectively. The peak at $\mathrm{m} / \mathrm{z} 734$ was attributed to PC (16:0/18:1). The blank sample underwent the whole fixing procedure and represented a tissue sample with no siderophores added. 
Aspergillus inactivation in one-hour treatment is illustrated in Fig. 6. Although the data show that $1 \%$ formaldehyde concentration could be enough, one has to be aware about an increased infectivity occuring during the microorganism passage throughout a host. In our model of experimental aspergillosis in rats (Pluhacek et al., 2016), we noticed that for the full inactivation of $A$. fumigatus isolated from lungs of infected animals a two day inactivation in $4 \%$ formaldehyde was actually needed for stopping the mycelial growth. After this intense inactivation, no fungus growth was observed either in liquid medium (MEB) or on agar plates (YM).

Although the pathogen inactivation represents certainly a mandatory safety feature, one cannot exclude the possible signal attenuation in MALDI or DESI spectra if formaldehyde crosslinking was used. In an experiment with neonatal rat lung homogenates, we evaluated the effect of formaldehyde, which was added to one of the sample sets. We prepared a series of lung homogenates mixed with two fungal siderophores, triacetylfusarinine $\mathrm{C}$ (TAFC) and ferricrocin (FC) in concentrations range $0.002,0.02,0.2,2$, and $20 \mu \mathrm{g} / \mathrm{g}$. The siderophore responses in MALDI mass spectra revealed merely negligible signal attenuation after tissue fixation (Fig. 7, top). A similar result was obtained with DESI imaging from a Prosolia Omni Slide ${ }^{\mathrm{TM}}$ glass (data not shown). In the case of siderophores, the ion responses in DESI were 2 orders of magnitude lower compared to those in MALDI mass spectra.

\section{Conclusion}

We reported a novel methodology for the multi-omics analysis of biological tissue samples. First, REIMS can be used to identify small molecule markers for specific tissue types or disease states without any sample pre-treatment. Next, pathogen inactivation (if necessary) and slide preparation for multimodal imaging approach in order to target various small molecules within the samples is described. Finally, a method to align and evaluate the different modality MSI and optical images with the use of fiducial markers is reported.

Acknowledgement. Ministry of Education, Youth and Sports of the Czech Republic (LO1509) and Czech Science Foundation (16-20229S), Slovak Grant Agency VEGA (2/0155/16), the grant 21610493 of the International Visegrad Fund and the grant 26240220096 of the Research \& Development Operational Programme funded by the ERDF.

\section{References}

Alexander J, Gildea L, Balog J, Speller A, McKenzie J, Muirhead L, Scott A, Kontovounisios C, Rasheed S, Teare J, Hoare J, Veselkov K, Goldin R, Tekkis P, Darzi A, Nicholson J, Kinross J, Takats, Z (2017): A novel methodology for in vivo endoscopic phenotyping of colorectal cancer based on real-time analysis of the mucosal lipidome: a prospective observational study of the iKnife. Surgical Endoscopy and Other Interventional Techniques 31, 1361-1370. https://doi.org/10.1007/s00464-016-5121-5

Balog J, Kumar S, Alexander J, Golf O, Huang JZ, Wiggins T, Abbassi-Ghadi N, Enyedi A, Kacska S, Kinross J, Hanna GB, Nicholson JK, Takats, Z (2015): In Vivo Endoscopic Tissue Identification by Rapid Evaporative Ionization Mass Spectrometry (REIMS). Angewandte ChemieInternational Edition 54, 11059-11062. https://doi. org/10.1002/anie.201502770

Balog J, Perenyi D, Guallar-Hoyas C, Egri A, Pringle SD, Stead S, Chevallier OP, Elliott CT, Takats, Z (2016): Identification of the Species of Origin for Meat Products by Rapid Evaporative Ionization Mass Spectrometry. J. Agric. Food Chem. 64, 4793-4800. https://doi.org/10.1021/acs. jafc.6b01041

Balog J, Sasi-Szabo L, Kinross,J, Lewis MR, Muirhead LJ, Veselkov K, Mirnezami R, Dezso B, Damjanovich L, Darzi A, Nicholson JK, Takats, Z (2013): Intraoperative Tissue Identification Using Rapid Evaporative Ionization Mass Spectrometry. Sci. Transl. Med. 5, 11. https://doi. org/10.1126/scitranslmed.3005623

Balog J, Szaniszlo T, Schaefer KC, Denes J, Lopata A, Godorhazy L, Szalay D, Balogh L, Sasi-Szabo L, Toth M, Takats, Z (2010): Identification of Biological Tissues by Rapid Evaporative Ionization Mass Spectrometry. Anal. Chem. 82, 7343-7350. https://doi.org/10.1021/ac101283x

Bolt F, Cameron SJS, Karancsi T, Simon D, Schaffer R, Rickards T, Hardirnan K, Burke A, Bodai Z, Perdones-Montero A, Rebec M, Balog J, Takats, Z (2016): Automated High-Throughput Identification and Characterization of Clinically Important Bacteria and Fungi using Rapid Evaporative Ionization Mass Spectrometry. Anal. Chem. 88, 9419-9426. https:// doi.org/10.1021/acs.analchem.6b01016

Cameron SJS, Bolt F, Perdones-Montero A, Rickards T, Hardiman K, Abdolrasouli A, Burke A, Bodai Z, Karancsi T, Simon D, Schaffer R, Rebec M, Balog, J, Takats, Z (2016): Rapid Evaporative Ionisation Mass Spectrometry (REIMS) Provides Accurate Direct from Culture Species Identification within the Genus Candida. Sci. Rep. 6, 10. https://doi. org $/ 10.1038 /$ srep36788

Castaing R, Slodzian, G (1962): Optique corpusculaire - premiers essais de microanalyse par emission ionique secondaire. Comptes Rendus Hebdomadaires Des Seances De L Academie Des Sciences 255, 1893-1899.

Cazares LH, Van Tongeren SA, Costantino J, Kenny T, Garza NL, Donnelly G, Lane D, Panchal RG, Bavari, S (2015): Heat fixation inactivates viral and bacterial pathogens and is compatible with downstream MALDI mass spectrometry tissue imaging. BMC Microbiol. 15. https://doi. org/10.1186/s12866-015-0431-7

Day JG, Stacey G (2007): Cryopreservation and freeze-drying protocols. Springer Science \& Business Media. https:// doi.org/10.1007/978-1-59745-362-2

Guenther S, Schafer KC, Balog J, Denes J, Majoros T, Albrecht K, Toth M, Spengler B, Takats Z (2011): Electrospray Post- 
Ionization Mass Spectrometry of Electrosurgical Aerosols. J. Am. Soc. Mass Spectrom. 22, 2082-2089. https://doi. org/10.1007/s13361-011-0230-9

Havlicek V, Lemr K, Schug KA (2013): Current Trends in Microbial Diagnostics Based on Mass Spectrometry. Anal. Chem. 85, 790-797. https://doi.org/10.1021/ac3031866

Chughtai K, Jiang L, Greenwood TR, Klinkert I, Amstalden van Hove ER, Heeren RMA, Glunde K (2012): Fiducial Markers for Combined 3-Dimensional Mass Spectrometric and Optical Tissue Imaging. Anal. Chem. 84, 1817-1823. https://doi.org/10.1021/ac203373h

Kinross JM, Muirhead L, Alexander J, Balog J, Guallar-Hoya C, Speller A, Golff O, Goldin R, Darzi A, Nicholson J, Takats Z (2016): iKnife: Rapid evaporative ionization mass spectrometry (REIMS) enables real-time chemical analysis of the mucosal lipidome for diagnostic and prognostic use in colorectal cancer. Cancer Res. 76, 4. https://doi. org/10.1158/1538-7445.AM2016-3977

Leveque N, Legoff J, Mengelle C, Mercier-Delarue S, N'Guyen Y, Renois F, Tissier F, Simon F, Izopet J, Andreoletti L (2014): Virological Diagnosis of Central Nervous System Infections by Use of PCR Coupled with Mass Spectrometry Analysis of Cerebrospinal Fluid Samples. J. Clin. Microbiol. 52, 212-217. https://doi.org/10.1128/ LCM.02270-13

Loibner M, Buzina W, Viertler C, Groelz D, Hausleitner A, Siaulyte G, Kufferath I, Kölli B, Zatloukal K (2016): Pathogen Inactivating Properties and Increased Sensitivity in Molecular Diagnostics by PAXgene, a Novel Non-Crosslinking Tissue Fixative. PLoS One 11. https://doi.org/10.1371/ journal.pone. 0151383

Mancone C, Ciccosanti F, Montaldo C, Perdomo AB, Piacentini M, Alonzi T, Fimia GM, Tripodi M (2013): Applying proteomic technology to clinical virology. Clin. Microb. Infect. 19, 23-28. https://doi.org/10.1111/1469$\underline{0691.12029}$

Mayers CP (1970): Histological fixation by microwave heating. J. Clin. Pathol. 23. https://doi.org/10.1136/jcp.23.3.273

Muirhead L, Kinross JM, Preece R, Speller A, Golf O, Goldin R, Darzi A, Takats Z (2015): A prospective, observational study of surgical and endoscopic rapid evaporative ionisation mass spectrometry (reims) for real time analysis of the colonic mucosal lipidome in colorectal cancer. Gut 64, A50-A51. https://doi.org/10.1136/gutjnl-2015$\underline{309861.102}$
Phelps D, Balog J, El-Bahrawy M, Speller A, Brown R, Takats Z, Ghaem-Maghami S (2016): Diagnosis of borderline ovarian tumours by rapid evaporative ionisation mass spectrometry (REIMS) using the surgical intelligent knife (iKnife). BJOG Int. J. Obstet. Gy. 123, E4-E4.

Placha K, Luptakova D, Baciak L, Ujhazy E, Juranek I (2016): Neonatal brain injury as a consequence of insufficient cerebral oxygenation. Neuro. Endocrinol. Lett. 37, 79-96.

Pluhacek T, Petrik M, Luptakova D, Benada O, Palyzova A, Lemr K, Havlicek V (2016): Aspergillus infection monitored by multimodal imaging in a rat model. Proteomics 16 , 1785-92. https://doi.org/10.1002/pmic.201500487

Prichystal J, Schug KA, Lemr K, Novak J, Havlicek V (2016): Structural Analysis of Natural Products. Anal. Chem. 88, 1033810346. https://doi.org/10.1021/acs.analchem.6b02386

St John ER, Rossi M, Pruski P, Darzi A, Takats Z (2016): Intraoperative tissue identification by mass spectrometric technologies. Trends Anal. Chem. 85, 2-9. https://doi. org/10.1016/j.trac.2016.05.003

Spengler B, Hubert M, Kaufmann R (1994): MALDI Ion Imaging and Biological Ion Imaging with a new Scanning UV-Laser Microprobe, Proceedings of the 42nd Annual Conference on Mass Spectrometry and Allied Topics, page 1041, Chicago, Illinois, May 29 - June 3, 1994.

Stoeckli M, Farmer TB, Caprioli RM (1999): Automated mass spectrometry imaging with a matrix-assisted laser desorption ionization time-of-flight instrument. J. Am. Soc. Mass Spectrom. 10, 67-71. https://doi.org/10.1016/ S1044-0305(98)00126-3

Strittmatter N, Jones EA, Veselkov KA, Rebec M, Bundy JG, Takats $\mathrm{Z}$ (2013): Analysis of intact bacteria using rapid evaporative ionisation mass spectrometry. Chem. Commun. 49, 6188-6190. https://doi.org/10.1039/c3cc42015a

Strittmatter N, Rebec M, Jones EA, Golf O, Abdolrasouli A, Balog J, Behrends V, Veselkov KA, Takats Z (2014): Characterization and Identification of Clinically Relevant Microorganisms Using Rapid Evaporative Ionization Mass Spectrometry. Anal. Chem. 86, 6555-6562. https://doi. org/10.1021/ac501075f

Verplanken K, Stead S, Jandova R, Van Poucke C, Claereboudt J, Vanden Bussche J, De Saeger S, Takats Z, Wauters J, Vanhaecke L (2017): Rapid evaporative ionization mass spectrometry for high-throughput screening in food analysis: The case of boar taint. Talanta 169, 30-36. https:// doi.org/10.1016/j.talanta.2017.03.056 